\title{
Choosing to Live with Harm? A Presentation of two Case Studies to Explore the Perspective of those who Experienced Adult Safeguarding Interventions
}

\author{
Kathryn Mackay
}

\begin{abstract}
Adult safeguarding often creates a tension for welfare practitioners between promoting an adult's autonomy and their duty to try to protect them from harm. Literature highlights the dangers of adopting simplistic notions of autonomy and capacity in assessing whether someone may be choosing to live with harm. Yet very little has been published about how adults at risk and family members experience the tension between autonomy and protection: what choices do they think they have and why might they choose one above another? The article starts to address this gap by utilising an ethic of care to explore the experiences of an adult at risk; and then a family member where older people were being harmed within family relationships. These accounts were drawn from a Scottish qualitative adult safeguarding study. They highlight how choice, autonomy and capacity are interconnected concepts; and that they can be compromised by a range of personal, relational and environmental factors. In addition they demonstrate how practitioners can support or limit the choices open to adults at risk and their family members. The ensuing discussion summarises the implications for practice and considers how voices of experience might be better captured in the future.
\end{abstract}

Key words: choice, adult safeguarding, capacity, autonomy, ethical dilemma, ethic of justice and ethic of care, case studies

\section{Introduction}

Adult safeguarding policies across the UK require practitioners to identify, investigate and where necessary protect an adult at risk of harm, abuse or neglect, if they are unable to safeguard themselves due to disability, mental health or frailty. At the same time practitioners should be supporting their autonomy. This tension between protective duties and supporting a person's autonomy presents ethical dilemmas for practitioners. A key challenge is trying to determine whether a person is freely choosing to live with harm; and one UK country has now formally introduced the concept of choice into their practice guidance. The Scottish Government has advised that a distinction needs to be drawn between: 'an adult (who) is unable to safeguard themselves, and one who is deemed to have the skill, means or opportunity to keep themselves safe, but chooses not to do so' (Scottish Government 2014,13).

Author: Kathryn Mackay is a Lecturer in Social Work at the University of Stirling. Correspondence to Faculty of Social Science, Colin Bell Building, University of Stirling, STIRLING, Scotland, FK9 4LA. Email: k.j.mackay@stir.ac.uk. 
Choice has been adopted, by successive UK governments, as a key value to inform the development and implementation of social care policy. Yet choice, in this context, is a contested concept and there is a large body of work that critically considers its assumptions and limitations. For example that it fails to acknowledge the structural factors such as poverty, age, race and gender that give some people more choice than others (Clarke et al. 2007; Glendinning 2008; Stevens et al. 2011). At the personal level it is criticised for depicting citizens as independent, rational and autonomous choice-makers; minimising the interdependent and relational nature of everyday life that an ethic of care seeks to highlight (Barnes 2011, Lloyd 2010). This underlines the importance of exploring choice from the experience of adults at risk and their families, and yet their perspective forms only a small part of the adult safeguarding research conducted so far (Graham et al. 2014; Preston- Shoot and Cornish 2014).

The author starts to address this gap by presenting the accounts of an adult at risk and of a family member, who were not related to each other, and who were interviewed in 2011 as part of a Scottish adult safeguarding research project (Mackay et al. 2011). The article first uses an ethic of care to problematize the concept of choice and draws upon social care and adult safeguarding research to highlight the personal and relational factors that may affect a person's ability to safeguard. Secondly an outline of the research methodology is provided before the personal accounts are presented. This leads to a discussion on how skills, means and opportunity of safeguarding might be usefully defined. The article's distinctive contribution lies in the deeper insight it offers into adult safeguarding dilemmas and choice from the perspective of an adult at risk and a family member.

\section{Choice, Capacity and the In/Ability to Safeguard}

This section starts with an exploration of choice as a policy value and sets out the critique offered by an ethic of care. It draws upon research to illustrate the persona and relational nature of choice from the perspective for older and disabled people. It then considers how such factors might also influence capacity before the emergent themes are brought together to try to define skills, means and opportunity in the context of adult safeguarding.

\section{Choice as a Policy Value}

The choice as a policy value is said to be individualistic because it devolves the responsibility for managing risk to the citizen (Ferguson 2007). It also assumes that people will make the 'right' or rational choice when faced with a decision regarding their welfare (Rabiee 2013). Clarke and Newman (2012) argue this promotes the idea of responsible citizenship where those who make poor choices may be viewed as undeserving of state support. It is illustrative of an ethic of justice in that it seeks to maintain a clear boundary, based on the principle of self-determination, between personal and state responsibility (Held 2006, Tronto 1993). Choice, therefore, is not a neutral concept but a product of 'ideological, cultural and political debate' about the role of welfare services (Barnes 2012, 61). The most recent changes in adult safeguarding law in England, Scotland and Wales provide one such example. Whilst all three governments agreed that risk of, as well as actual harm or abuse, were grounds for investigation they imposed different thresholds. The terms abuse or neglect were 
adopted in Wales and England but Scotland adopted a lower threshold of harm (Department of Health 2014, Scottish Government 2014, Welsh Assembly 2014). This means that instances of harm that might lead to intervention in Scotland may not trigger a safeguarding response elsewhere in the UK until they reach greater severity.

The concept of mental capacity, from an ethic of justice perspective, is key to maintaining the boundary between personal and state responsibility. If someone is assessed as having capacity they are self-determining; and, in this context, freely choosing to live with harm, even if that harm is severe (McDermott 2011). Adult safeguarding policy does caution against inability to safeguard being equated with cognitive capacity (Department of Health 2014, Scottish Government 2014, Welsh Assembly 2014). Yet this may be difficult to achieve within the more established dominant discourse of choice $v$ protection in social care policy (Barnes 2012, Cornwall Adult Protection Committee 2007, Fyson and Kitson 2007). Here in/capacity sits alongside other binaries that place independence, autonomy, choice and control on one side and welfare dependency and paternalism on the other (Fyson and Kitson 2007, McDermott 2011, Preston-Shoot and Cornish 2014).

An ethic of care challenges such binaries arguing that a lack of independence or autonomy does not automatically lead to dependency. Instead there is a need to 'rethink our conceptions of human nature to shift from the dilemma of autonomy or dependence to a more sophisticated sense of human interdependence' (Tronto 1993,102). If interdependence is an everyday fact of life, then autonomy itself is relational: something that is nurtured, as well as constrained, by other people (Christman 2014, Mullin 2011, Sevenhuijsen 1998). Barnes (2011) and Lloyd (2010) have therefore used the ethic of care to highlight how UK adult care policies, such as personalisation, focus on the informational and practical elements of accessing and gaining support but fail to acknowledge the personal and relational elements of these very processes (Barnes 2011 and 2012, Lloyd 2010). In summary then it is better to see choice as a process of choosing rather than as a one off event; and an important element of choosing may be quality of the relationships between the person and significant others in their life, including professionals.

\section{Making a choice}

UK social care policies, as noted above, presume a person who has been given information about the various options will make an objective or rational choice. A major UK longitudinal study of disabled people and older adults who were facing major decisions around medical intervention, housing or personal support challenges this rationalistic approach. The findings draw attention to the lack of available information and advice, but they also highlight the influence of identity, emotion and relationships on choice (Rabiee and Glendinning 2010).

Firstly, in relation to identity, Rabiee (2013, 9) reported that 'some [people] prioritised choices that maintained their sense of independence in the shorter term, even at the risk of their future independence'. Rabiee (2013) observed some people's decisions were driven not by future proofing but by the need to reinforce a sense of self that was being challenged by poor health and impairment. For example some people made choices that better preserved their identity as a parent or partner; or reflected 
their attachment to their current home. Secondly the study highlighted the role of emotion. It found that some choices were seen as so difficult that people delayed or avoided making a choice: 'Most of the emotions discussed were negative, such as fear, worry, stress, isolation and anger.... People reported a downward spiral whereby their perceived difficulty in making decisions led to anxiety and further deteriorations in health.' (Glendinning and Baxter 2013, 443).

These personal dimensions of choice and decision-making: identity and emotion within the context of their close relationships are also reflected in the small body of safeguarding literature. Mowlam et al. (2007) interviewed older people, within a wider UK study into elder abuse. The interviewees had not necessarily experienced abuse but their views highlight the difficulties people might experience. Firstly some interviewees expressed reluctance about divulging possible harm due to fear, anxiety and shame (Mowlam et al. 2007). A portion of their interviewees were also concerned about the potential negative outcomes for their partner, or family member, if they spoke out in such situations. This latter point highlights an additional dimension: that relationships are rarely all good or bad, and that concern for the harmer may stop people seeking help. Responding to the harmer's need might therefore also be necessary. A point that was made by Held (2010) in connection to domestic violence where the pursuit of justice through courts might not, on its own, reduce risk of harm for the victim.

The reluctance to disclose harm arose also within a research project that sought the views of disabled people about risk (Faulkner 2012). Some participants were concerned that such disclosures might be interpreted by practitioners as an inability to live independently. Being seen as 'vulnerable' was said to threaten their own sense of self as someone in control of their lives. Finally a Scottish review of available smallscale adult safeguarding evaluations and research projects revealed factors that supported or limited adults' at risk and their family members' participation in investigatory processes (Improving Participation Project Team 2013). Of particular relevance to this discussion were the findings that poor mental health and anxiety stopped people from seeking help but also that it affected their ability to process information and advice given by practitioners.

This research context confirms the influence of personal and relational factors on decision-making about significant welfare concerns. It suggests that choosing to live with harm may be influenced by the perceived threats to one's emotional wellbeing; to the welfare of the harmer, and to one's identity. Bergeron's (2006) observations, as a counsellor for older adults who experienced abuse, support these research findings. She suggests that the strength of such feelings, combined with poor mental health might lead to a person's sense of self becoming so precarious that they feel they have no option but to remain in an abusive situation. This suggests the concept of capacity, as well as choice, requires careful appraisal.

\section{Capacity to safeguard}

Changes in mental capacity law across the UK reflect the move away from viewing incapacity as a global condition to one that is decision-specific (Johns 2014). Yet decision- specific capacity assessments can suffer from the same rationality approach as choice: focusing on one issue at a fixed point in time (Brown 2011). This could lead to a continued all or nothing approach: if someone can be said to have the 
capacity to make a choice then they are self-determining and welfare services should not intervene. McDermott's Australian study of workers' responses to self-neglect and squalor provides an example of this. She found that some workers took a 'strict or detached view of autonomy' akin to an ethic of justice: intervention was 'only appropriate when people are legally determined to lack decision-making capacity' (McDermott 2011, 60). In contrast other workers demonstrated an approach based on an ethic of care: trying to establish a relationship with the person in the hope that through time and building trust some agreed changes could be made to reduce risk.

Part of the problem in assessing capacity is the conflation of decisional capacity with executional capacity (Braye, Orr and Preston-Shoot 2011). Decisional capacity is the cognitive ability to think through a problem and its possible solutions. It can, as noted above, be reduced by poor mental health (Improving ASP Participation Project Team 2013). In addition a person's own life history and resulting sense of self might also skew their view of the issues or options for action (Brown 2011, Braye, Orr and Preston-Shoot 2011). Decisional capacity can also vary across different aspects of a person's life (Johns 2014). For example a person with mild to moderate learning difficulties might be able to understand many practical aspects of everyday life but may struggle to comprehend the difference between healthy or harmful relationships (Fyson 2009). Executional capacity is the ability to put a choice into action. For example someone may be physical incapable of taking an action but they can instruct someone to execute it on their behalf. People may also need other types of support to put their decision into action such as getting safely to a place of refuge. There are more challenging aspects of executional capacity to assess such as whether someone has enough emotional strength or a belief that change is possible with or without support; and whether they are under the undue influence of others not to take action (Mackay et al. 2012).

Failure to recognise the contextual and contingent nature of capacity might lead to failure to see that a 'person is genuinely out of their depth' (Brown 2011, 195). Steven Hoskin, a young man with learning difficulties, who was murdered by people who 'befriended' him may have been one such person (Fyson and Kitson 2007). A range of professionals had contact with Steven and focussed on the presenting issue for their own agency: reports to housing about anti-social behaviour or medical staff treating his injuries. Each appeared to view him as self-determining. In contrast, the serious case review assessed Steven as latterly having very little choice or executional capacity because he was subject to coercion by others (Cornwall Adult Protection Committee 2007).

\section{Skill, Means and Opportunity to Safeguard}

This literature overview, drawing upon an ethic of care, highlights the need to be attentive to the interdependent, relational and personal nature of choosing, or not, to live with harm. This suggests a broad definition of the skills, means and opportunity. Skills are more than cognitive capacity; and they might include the ability to concentrate, to think things through and self-awareness about how one's history and identity might influence choices and actions. Means extend beyond available information, advice and service, to personal resources such as confidence and strength of character. It will also include sources of support that the person might have around 
them. Dictionaries define opportunity as a favourable occasion or a good chance. In some ways it overlaps with means in that it could be availability of the support of friends and family, or the knowledge of welfare resources potentially open to them. However it also speaks to the more hidden psychological aspects: a belief that change for the better might be possible, that they are worth the effort; and that they trust someone enough to believe that they will walk alongside them along an uncertain path. In short this initial definition recognises the relational nature of autonomy and in this respect practitioners who undertake safeguarding work might be viewed as an opportunity as well as a means.

\section{Research Study}

This qualitative research study (Mackay et al. 2011) sought to explore adult safeguarding from the perspective of social service practitioners and adults who had been defined as at risk of harm. Only six adults at risk agreed to participate and this led to the inclusion of family members, which elicited only one further participant (see next section for fuller discussion of this decision). The study was funded by and conducted within three Scottish local authorities in 2010/11. Ethical approval was given by the university and the local authorities involved. A previous publication (Mackay et al. 2012) explored the perceptions of the 29 practitioners, who participated in the study, on the impact of new Scottish adult safeguarding legislation. It highlighted majority views around greater clarity of role, more priority being given to supporting adults at risk and improved interagency working. It also noted that some practitioners expressed anxieties around assessing whether adults at risks were making informed choices and it was this finding that led to a secondary analysis of the other transcripts.

\section{Methodology}

This section focuses on the methodology for the adults at risk and the family member. Adults at risk are defined as vulnerable research participants and are also a group who are hard to reach (Mowlam et al 2007). A key ethical consideration was establishing a sample and access protocol that avoided distress and ensured informed consent. This led to the decision to involve only those who had ongoing involvement with social services. A manager in each agency identified potential participants and asked the lead worker if there were any reasons, such as illness or ongoing harm, not to invite the person to take part in the research. Those not ruled out were then visited by their worker who explained the research with the use of an easy to read information sheet and consent form. This process elicited only six service users. The decision to approach family members of adults at risk was taken with the aim of increasing the number of voices from people with experience. It was decided that these family members should not be related to adults at risk who had already been contacted. Family members were not to be seen as proxies for the adult at risk but would be asked to share their own views of the safeguarding process. As noted above only one family member agreed to be interviewed and this may have been due to the decision being taken towards the end of the data collection stage. In contrast a project, to develop an adult safeguarding outcome measure, set out from the start to gain the views of both adults at risk and family members; and this produced a much better response (Norrie et al. 2015). 
Each person was interviewed once to explore in general terms the support they received, what had been helpful or unhelpful about the safeguarding process, and what might have changed as a result. There was potential for discussion about past events to cause emotional upset so interviewers took their cue from the interviewees and respected the choices they made about disclosure. In addition the local authority had agreed to respond to any need for additional support if the interviewee became distressed. Interviews were recorded and fully transcribed.

\section{Limitations}

The chosen cases studies offer original insights but they have been picked from what was already a very small sample. Therefore no claims are made about their generalisability. In addition the methodology did not set out to take a specific narrative approach. Nora and Sue (pseudonyms) were selected because they gave the clearest account of their thoughts and feelings of an adult. Future projects could try to avoid this potential bias by giving more time and planning around facilitating communication. In addition building in a second interview would have given both respondent and researcher time to reflect on their discussion and the opportunity follow up on emergent themes. That said the in-depth presentation of two participants' experiences does provide a rich insight into choice and the in/ability to safeguard that can be built upon in future work.

\section{Preparing the Case Studies}

The author read the interview transcripts in depth and the case studies were written from first contact with social work through to the time of the interview. She regularly referred back to them to check that quotes were not taken out of context. The aim was to give a faithful account of their experience. The author has used quotation marks to denote their exact use of words. Elsewhere the author has used terms such as 'described' or 'expressed' to denote a paraphrasing of something that came directly from the interviewees. All identifying features have been changed to preserve anonymity. The quotations have been altered in three ways to help the reader. Scottish words have been placed with their English equivalent; identifying information has been replaced by neutral descriptions in brackets and a series of full stops signifies that some phrases have been removed where the interviewee was repeating themselves or struggling to find an expression that reflected their thoughts.

\section{Inability to Make a Choice}

Nora was in her late sixties and was not in receipt of services. A family member made the referral to social work. Nora had no physical or cognitive impairments and her experience demonstrates how capacity to make and then act on choices can be compromised in other ways. She explained that Pete, her son, had a substance misuse problem and moved in with her after becoming homeless. Nora described how he began to exert his will over hers till in the end he controlled many aspects of everyday life:

I wasn't allowed to open my curtains...but it was all different things. He used to wake me up during the night because he was coming down from the thing [a drug induced high]... and he would get angry 
Nora lacked confidence: she described herself as a quiet person and 'not forward enough'. Also she did not know who to seek help from: she said she couldn't 'have went for it herself because I didn't know what to do'. Nora's narrative was dominated by two distinct elements that stopped her addressing the harm. The first was that poor mental health compromised her decision-making ability and the second was that she felt responsible, as a mother, for her son and felt unable to put him out because 'he's got disabilities'. Nora was able to express her despair at the time of the safeguarding investigation:

I just felt I was in a hole and couldn't get out...It was dreadful. And it got to the stage that... I just used to go to bed at night and just hope I didn't wake up in the morning.

The arrival of two social workers at her door posed a threat as a well as an opportunity: risk of aggravating her fragile mental health but at the same time the possibility of a way out of the harm:

Although I was scared...I know it was good because I was hoping they could help me. It was what I wanted, somebody to help me.

The next passage reveals her internal struggle between what she might be losing as well as gaining. It also reflects her difficulty in processing the social workers' information and advice (ASP Improvement Team 2013):

I didn't just say right I'm going...I had to think what would happen and all the other things were jumbling inside my head... and it was leaving my house, it was the thought of leaving it and then my son wasn't going to be there when I got back.... They didn't rush me or anything. I could take my time. They never made me decide anything quick. They would say think about it... And that's what helped me....... It was marvellous (in the safe place). It was like a holiday...Because it got me away... just felt I had time to think.

Nora's account suggests the practitioners recognised her dilemma and compromised decisional capacity. She repeated often that they were patient and understanding: they were always ready to explain things and spend time with her. They were also seemed aware of her inability to put wishes into action i.e. her lack of executional capacity (Braye, Orr and Preston-Shoot 2011). They offered a safe house for her and homeless accommodation to Pete:

I couldn't do that put him out on the street. And they... what they done, was put me in a small house for two weeks then they took my son away (to a homeless unit)... It made me feel guilty cos l'd put him into that.

These feelings of guilt illustrate how maternal loyalties combined with poor mental health and her pre-existing lack of confidence impaired her ability to safeguard herself. Nora wanted the harm to stop but her dilemma was around not only weighing the costs and benefits for herself but also for her son (Mowlam et al. 2007). Therefore the help offered to Pete was a key factor in tipping the balance towards a good chance to take. 
At the time of the research interview, more than a year later, Nora was continuing to receive emotional and practical support, and described herself as slowly becoming more confident. Her son had his own tenancy and had been offered support with his own problems. Initially Nora had not wanted to see him but later this changed and the social worker arranged supervised contact. Nora now felt more in control: she allowed him to visit her home but he had to phone in advance:

I mean I can say to him, right it's time to go .... I couldn't do that before.

The nature of their relationship had changed and this was Nora's one source of regret:

Although I still see him, I love him ....but it's... that closeness it isn't there anymore.

This loss was heavily felt at times but overall the gains in her life appeared to outweigh this; and Nora talked positively about her future.

\section{Independence at all Costs?}

Sue was a family member of Mr and Mrs Brown, an older couple. Mrs Brown was in the later stages of a degenerative condition that had left her with very little mobility but her cognitive abilities remained unaffected. Mrs Brown was determined to stay at home and Mr Brown, along with carer workers, provided a lot of personal and practical support. However Mr Brown's increasing dependence on alcohol, sometimes consuming to the point of unconsciousness, led to variable care. He would also, on occasion, refuse to let care workers in. Sue was already involved in trying to improve the care for Mrs. Brown when there was an instance of domestic violence.

Emotions were running high...I was discussing various options...I couldn't calm him down and there was a fear for me about her safety.

Sue called the out of hours social work service who then contacted the police. Mrs. Brown was reluctant to see her husband charged and the police were reluctant to take an older man with health problems into custody.

The onus then fell on social services to respond to the immediate risk. Overnight care workers were put in till their care manager could arrange respite care. The couple did not wish to be separated but agreed to go into a care home together. The care home turned out to be a poor experience for them both. Sue reflected on this emergency respite placement: 
It was the worst thing I ever done, with hindsight, me and (the practitioner) have spoken about that, I think she panicked and I panicked... I used to mention respite to Mrs Brown thereafter and she would physically shake.

Sue described how she took over the running of the care package, through a direct payment, in an effort to improve the quality and consistency of support. She continued to do this until Mr Brown became ill and died; and Mrs. Brown moved into a care home of her choice. Sue recounted several incidents where care workers could not get access or where Mr Brown's drinking lead her being called upon to address professionals' concerns. From Sue's perspective the particular incident described above was the only time any professional raised the question of adult safeguarding. Sue's ability to get into the house and her strength of character can be seen as a resource, or means of safeguarding, that all agencies involved drew upon:

And I think from them it was, like, it's fine because Sue's about and she knows and she can coordinate and she'll sort that out and she'll not let anything happen...

I remember one time the GP found Mr. Brown, at eleven o'clock in the morning, absolutely comatose in the hall... and had phoned Home Care.... Home Care then phoned, I think, Social Work and.... I remember saying to them, look, I'm really, really sorry but, you know, there's three services here, all have a duty of care to Mrs Brown.

Sue talked explicitly about choice at times during her interview: choices Mrs Brown made and then secondly the choices she felt she had. Firstly Sue acknowledged Mrs. Brown's capacity to choose:

I know she has capacity and I know that she had choices to make but I had huge concerns......and there would have been several phone calls out of hours with regards to...l've got concerns because (Mr. Brown) is unable and incapable.

The interviewer asked Sue if anything else could have been done:

I have struggled with this... Who am I to make those kinds of choices for her? In as much as I had huge concerns ... is it right for me to say, we'll put her into care? ... But if we had separated them what would her quality of life (have been). ..My concern was because she had no quality of life...but then that was my judgement ...maybe her quality of life was being with him.

Sue was an able person, she felt responsible for Mrs Brown and it was having an impact her life. She felt she was left with little choice herself and she recounted what she once said to Mr. and Mrs. Brown after being called out:

The only people, you know, in this whole situation that have got choices is you two and your choices are impacting on my ability to (work and have a life of my own).

Sue's account included a lot of telephone contact with the workers involved though there was a sense that this was focussed more on responding to incidents as they arose. Given the ongoing dilemmas and difficulties she experienced in trying to 
keep Mrs Brown safe, and dealing with Mr. Brown's challenging behaviour, the research directly asked Sue if the practitioner had discussed these with her. Sue replied "No". She then went on to explore what she might have wanted to discuss:

I would have liked to have known (about the legalisation).....for me to understand their methodology and mindset, you know, say, today, right, under this, because she's got capability, however, what we could do, you know,.... and where the boundaries are and where the problems are but....all I just kept on getting was capacity.

It is possible that the family's decision to use direct payments which Sue then supervised may have led professionals to take a less proactive role: viewing Sue, as she noted above, as someone who got in and sorted things out.

\section{Discussion}

Nora and Sue offer rich insights into how they experienced dilemmas around autonomy, harm and protection. Nora wanted the harm to stop but did not want to place her son in a worse situation. Sue wanted to respect Mrs. Brown's wish to stay at home with her husband but feared she could not keep her safe. Sue's experience is not intended to be an example of harm that was not addressed in contrast to Nora's positive outcomes. Indeed Mrs Brown's objective was staying at home as long as she could. It does though demonstrate that sometimes harm cannot be avoided if an adult's informed choices are to be respected (McDermott 2011, Preston-Shoot and Cornish 2014). Together they powerfully highlight the range of factors, beyond cognitive capacity, that might lead someone to choose to live with harm; or to wish for the harm to stop but be unable to execute that desire. They underline that autonomy, choice and capacity are not inherent personal characteristics but are aspects to daily living that are constrained and nurtured within relationships.

Nora's and Sue's accounts support the initial definitions offered for the skills, means and opportunity of ability to safeguard. First that decision-making skills cannot be assessed on levels of cognitive impairment alone (Brown 2011); and that capacity is both decisional and executional in nature (Braye, Orr and Preston-Shoot 2011). Sue's narrative suggests that no-one felt Mrs Brown lacked decisional capacity: her wishes were clear as were her reasons. In contrast Nora's decisional capacity was compromised by poor mental health (Baxter and Glendinning 2013, Bergeron 2006, Brown 2011, Braye, Orr and Preston-Shoot 2011). The practitioners supported Nora to re-gain decisional capacity: helping her to think through the potential issues and options. From Nora's viewpoint time and patience were key elements of their approach. Other people might need more specialist counselling or use of assistive communication technologies.

Secondly Nora and Mrs Brown both lacked executional capacity (Braye, Orr and Preston-Shoot 2011) and it was the relationship with others that gave them the means to implement their choice. Sue was pivotal to Mrs. Brown staying at home: someone who organised the care and responded when there were crises. Without such a family member Mrs. Brown may not have been afforded the opportunity to continue to live with her husband. What may have been lacking for Sue was the recognition of her own dilemmas and support needs (Mullin 2010). There is a sense that she had been left 
with a residue, an effect recognised in practitioners who have worked with irresolvable dilemmas (Banks and Williams 2005). In contrast, there were two instances within this study where social workers talked explicitly of arranging separate support for parents when they recognised that their support for the daughter's or son's autonomy conflicted with the parents' desire to keep them safe. This raises questions about whether some ethical dilemmas are better recognised than others and whether this varies by type of familial relationship.

Nora's account highlights a range of practical means: information, safe house, respite care, home support and homeless facilities. The relationship built between her and the social workers appears key to Nora taking the opportunity: they helped her to believe that there was a good chance of a positive outcome. Nora's account stands out as an example of the relationality of autonomy (Barnes 2012, Christman 2014 and Tronto 1993), and she continued to get support to rebuild her life. Nora's experience also underlines the value of supporting the harmer (Held 2006). The work undertaken, including supervised contact between an adult harmer and harmed has yet to receive attention within adult safeguarding literature but it was an important part of Nora's narrative. It also took place within three other cases in this research. It therefore merits further exploration as a means to improve a person's ability to safeguard themselves in the longer-term.

\section{Conclusion and Recommendations}

This exploration of choice, autonomy and capacity through two voices of experience, confirms that choosing, or not, to safeguard oneself from harm is a complex phenomenon. The accounts stress the need to get away from binary understandings around justice and care; in particular those around in/dependence and in/capacity. Assessing someone's safeguarding ability should not be viewed as decision-specific events: it is a process that may take quite a long time. Also that these interconnected concepts need to be placed in the everyday context of people's lives: their sense of self and motivations, emotional wellbeing, the nature of their relationships and their attachment to their existing homes. Without embedding these understandings into practice simplistic applications of these concepts may continue. In addition we need to know more about how adults at risk and their families experience and try to minimise harm, and what might help them when they faced with an irresolvable dilemma. The recommendations, therefore, focus on practice and research.

Safeguarding guidance and training might better acknowledge and engage with dilemmas that adults at risk and their family members may face, and with the complexity around assessing choice and capacity. This also has implications for practitioners and those who manage them. Practitioners may require more time to undertake investigations and they need the type of supervision that promotes discussion of the uncertainties around ability to safeguard rather than focus on whether someone has cognitive capacity of not. It has to be acknowledged that this recommendation is being made at a time of prolonged public service cuts. One recent safeguarding study has reported that some practitioners were under pressure from managers to process adult safeguarding investigations quickly (Preston-Shoot and Cornish 2014). 
These two accounts reflect only a small proportion of the types of dilemmas that might surface in adult safeguarding. There is a need to explore the experiences of a wider range of people who live in different environments, and are subject to different types of harm. There is though difficulty in accessing adults at risk and their family members. So other methods to access this disparate group are required. McDermott (2011) utilised observation in agencies to explore practitioners' work with people who self-neglect. This will not work in crisis situations, as described by Sue, where the value of the knowledge gained has to be balanced with the extra demands it places on participants at a time of stress. However it might be possible in less difficult situations. An action research project could usefully explore other methods. For example triad discussions between the adult at risk and the lead practitioner could be facilitated by a researcher or another worker. Such projects could involve other services users and family members as co-researchers (Improving Participation in ASP Team 2013).

Yet this will only capture the narratives of those who have ongoing contact with services. A way has to be found to seek the perspectives of people where investigations led to no further action or those who may not have been investigated at all. Local authorities often send out surveys as part of their own auditing but get few responses. Other avenues such as advocacy services, carer groups and use of social media may prove more fruitful avenues. These methods are all more time consuming but without them the empirical base of adult safeguarding may remain one sided.

\section{References}

Banks, S. \& Williams, R. 2005. "Accounting for Ethical Difficulties in Social Welfare Work”. British Journal of Social Work 35 (7): 1005-1022. doi: 10.1093/bjsw/bch199

Barnes, M. (2011) "Abandoning Care? A Critical Perspective on Personalisation from an Ethic of Care", Ethics and Social Welfare, 5(2): 153-167.

Barnes, M. 2012. Care in Everyday Life: An Ethic of Care in Practice, Bristol: The Policy Press.

Bergeron, L. R. 2006. "Self-determination and Elder Abuse: Do We know Enough?" Journal of Gerontological Social Work, 45(3):81-102. doi:10.1300/J083v46n03_05

Braye, S., D. Orr and M. Preston-Shoot. 2011. "Conceptualising and Responding to Self-neglect: The Challenges for Adult Safeguarding." Journal of Adult Protection 13(4):182-193. DOI: 10.1108/14668201111177905.

Brown, H. 2011."The Role of Emotion in Decision-making", The Journal of Adult Protection 13(4): 194 - 202. doi: 10.1108/14668201111177932.

Christman, J, 2014. "Relational Autonomy and the Social Dynamics of Paternalism, Ethical." Theory and Moral Practice 17:369-382. 
Clarke,J., J. Newman, N. Smith, E. Vidler and L. Westmarland. 2007 Creating Citizenconsumers: Changing Publics and Changing Public Services, London: Sage

Publications Limited.

Clarke, J. and J.Newman. 2012."The Alchemy of Austerity." Critical Social Policy 32(3): 299-319. doi:10.1177/0261018312444405.

Cornwall Adult Protection Committee. 2007. The Murder of Steven Hoskin, a serious case review, Executive Summary, available online at:

https://www.cornwall.gov.uk/media/3630285/APC-Item-4-SCR-SH-recommendationsand-action-plan-Dec20071.pdf. (accessed 1 March 2015)

Department of Health. 2014 The Care Act 2014: Care and Support Statutory Guidance, available online at: https://www.gov.uk/government/publications/care-act2014-statutory-guidance-for-implementation (accessed 23rd August, 2015)

Faulkner, A. 2012. "The right to take risks." Journal of Adult Protection 14(6):287-296. http://dx.doi.org.10.1108/14668201211286066.

Ferguson, I.2007. "Increasing User Choice or Privatising Risk? The Antimonies of Personalization." British Journal of Social Work 37(3): 387-403.

doi:10.1093/bjsw/bcm041.

Fyson, F. 2009 "Independence and Learning Disabilities: Why we must also Recognise Vulnerability." Journal of Adult Protection 11(3): 18-25.

doi:0.1108/14668203200900018.

Fyson, R. and D. Kitson. 2007. "Independence or Protection does it have to be a Choice? Reflections on the Abuse of People with Learning Disabilities in Cornwall." Critical Social Policy 27(3):426-436. doi:10.1177/0261018307078850.

Glendinning, C. 2008. "Increasing Choice and Control for Older and Disabled people: A Critical Review of new Developments in England." Social Policy and Administration 42(5):451-469. DOI: 10.1111/j.1467-9515.2008.00617.

Glendinning, C. and C. Baxter. 2013. "The Role of Emotions in the Process of making Choices about Welfare Services: The Experiences of Disabled People in England." Social Policy \& Society, 12(3): 439-450. doi:10.1017/S1474746413000055.

Graham, K., C. Norrie, M. Stevens, J. Moriarty, J. Manthorpe and S. Hussein. 2014. "Models of Adult Safeguarding in England: A Review of the Literature." Journal of Social Work, advance access, first published on November 7, 2014. doi:1468017314556205.

Held, V 2010. "Can the Ethics of Care Handle Violence?" Ethics and Social Welfare, 4(2): 115-129. 
Improving ASP Participation Project Team. 2013. A Project to Support More Effective Involvement of Services Users in Adult Support and Protection Activity, Edinburgh: Scottish Government.

Lloyd,L. 2010. "The Individual in Social Care: The Ethics of Care and the 'Personalisation Agenda' in Services for Older People in England" Ethics and Social Welfare 4 (2):188-202.

Johns,J. 2014. Capacity and Autonomy,Houndsmill, palgrave macmillan

Norrie, C., C. Cartwright, P. Rayat, M.Grey, J. Manthorpe (2015) "Developing an adult safeguarding outcome measure in England", The Journal of Adult Protection, 17(5):275 - 286. Doi:10.1108/JAP-12-2014-0039.

Mackay,K, C. McLaughlan, S. Rossi, J. McNicholl, M. Notman and D. Fraser. 2011. Exploring how Practitioners Support and Protect Adults at Risk of Harm in the light of the Adult Support and Protection (Scotland) Act 2007, Stirling: University of Stirling. Available online at:https://dspace.stir.ac.uk/bitstream/1893/3524/1/ASP\%20research\%20report\%20final x.pdf, (accessed 30/01/15)

Mackay,K., Notman, M., McNicholl, J., Fraser,D., McLaughlan, C. and Rossi,S. 2012. 'What difference does the Adult Support and Protection (Scotland) 2007 make to social work service practitioners' safeguarding practice?' Journal of Adult Protection 14 (4): $197-205$.

McDermott, S. 2011. "Ethical Decision-making in Situations of Self Neglect and Squalor among Older People" Ethics and Social Welfare, 5(1): 52-71. doi: 10.1080/17496535.2011.546179.

Mullin, A. 2011. "Gratitude and Caring Labor" Ethics and Social Welfare, 5(2):110-122.

Mowlam, A., R. Tennant, J. Dixon, and C. McCreadie. 2007. UK Study of Abuse and Neglect of Older People: Qualitative Findings, London, Department of Health.

Preston-Shoot, M. and S. Cornish .2014. "Paternalism or proportionality? Experiences and outcomes of the Adult Support and Protection (Scotland) Act 2007", The Journal of Adult Protection 16(1):5 - 16. doi:10.1108/JAP-02-2013-0006.

Rabiee, P. 2013. "Exploring the Relationships between Choice and Independence: Experiences of Disabled and Older People", British Journal of Social Work 43(5): 872888. doi:10.1093/bjsw/bcs022.

Rabiee, P. and C. Glendinning. 2010. "Choice: What, When and Why? Exploring the Importance of Choice to Disabled People" Disability \& Society, 25(7):827-839. doi:10.1080/09687599.2010.520896.

Scottish Government. 2014. Adult Support and Protection (Scotland) Act 2007: Revised Code of Practice, Edinburgh: Scottish Government, available online at: http://www.gov.scot/Publications/2014/05/6492/1 (accessed 18 March 2015) 
Sevenhuijsen, S. 1998. Citizenship and the Ethics of Care: Feminist Considerations on Justice, Morality and Politics, London, Routledge.

Stevens, M., C. Glendinning, S. Jacobs, N. Moran, D. Challis, J. Manthorpe, J.L. Fernandez, K. Jones, M. Knapp, A. Netten, and M. Wilberforce. 2011. "Assessing the Role of Increasing Choice in English Social Care Services", Journal of Social Policy 40(2):257-274. doi: 10.1017/S004727941000111X.

Tronto, J. 1993. Moral Boundaries: A Political Argument for an Ethic of Care, London: Routledge.

Welsh Assembly. 2014 The Social Services and Well-being (Wales) Act 2014 available online at: http://gov.wales/topics/health/socialcare/act/?lang=en (accessed $23^{\text {rd }}$ August 2015) 